\title{
Line Creek Mine: Coal Processing and Quality Control
}

\author{
J. J. M. Van den BROEK**
}

\section{TABLE OF CONTENTS}

1. INTRODUCTION

2. COAL PROCESSING

2.1 Run-Of-Mine Coal Circuit

2.2 Thermal Coal Preparation Plant

2.3 Metallurgical Coal Preparation Plant

2.4 Refuse Disposal

2.5 Rail Transportation

3. THE CLOSED WATER CIRCUIT
3.1 Operating Description

3.2 Experience To-Date

4. QUALITY CONTROL PROGRAM

4.1 Mine

4.2 Breaker Station

4.3 Raw Coal Silos

4.4 Coal Preparation Plant

4.5 Loadout

5. CONCLUSION

\begin{abstract}
Crows Nest Resources' Line Creek Mine is one of five new Western Canadian Mines to have come on stream during the last two years.

As a second generation mine in S.E. British Columbia, Line Creek has been able to take advantage of 10 vears prior operating experience by other coal producers in the area. This experience provided an increased understanding of the specific mining and processing conditions required for Rocky Mountain coals and has contributed to a smooth plant start-up and stable operation. This paper describes the Line Creek operation and highlights two aspects of the preparation process - the closed water circuit and the product quality control program.

For the closed water circuit design, all process water is clarified and re-cycled within the confines of the plant building. Fine waste material is recovered by continuous belt filter presses and is combined with the coarse refuse for disposal on a dry basis.

The product quality control program has been made in integral part of the Line Creek operation. It includes pre-production drilling, selection of the coal seam mining sequence, raw coal blending, in-plant process adjustments, and clean coal quality monitoring at the plant outlet and the train loadout. Responsibility for quality control starts at the operator level, and emphasizes fast response to changing plant feed conditions.
\end{abstract}

\section{INTRODUGTION}

The Line Creek Mine is operated by Crows Nest Resources Limited, a wholly owned subsidiary of Shell Canada Resources Limited. The operation is located some 25 kilometers north of Sparwood in southeast British Columbia, Canada. (Figure 1)

The Line Creek coal deposit is part of the Upper Elk Coalfield in the East Kootenays. Line Creek coal is characterized as a low sulphur, medium volatile bituminous coal and is a high quality blend coking coal. Coal close to the outcrops is of low FSI and is marketed as thermal coal. Typical specifications for both clean coal products are shown in Table 1.

The present pit at the south end of the Line Creek Ridge has a total thermal and metallurgical

* 昭和59年 6 月13日本会第72回例会において発表

** Preparation Plant Manager, Crows Nest Resources Ltd.

昭和59年 5 月 28 日受理 


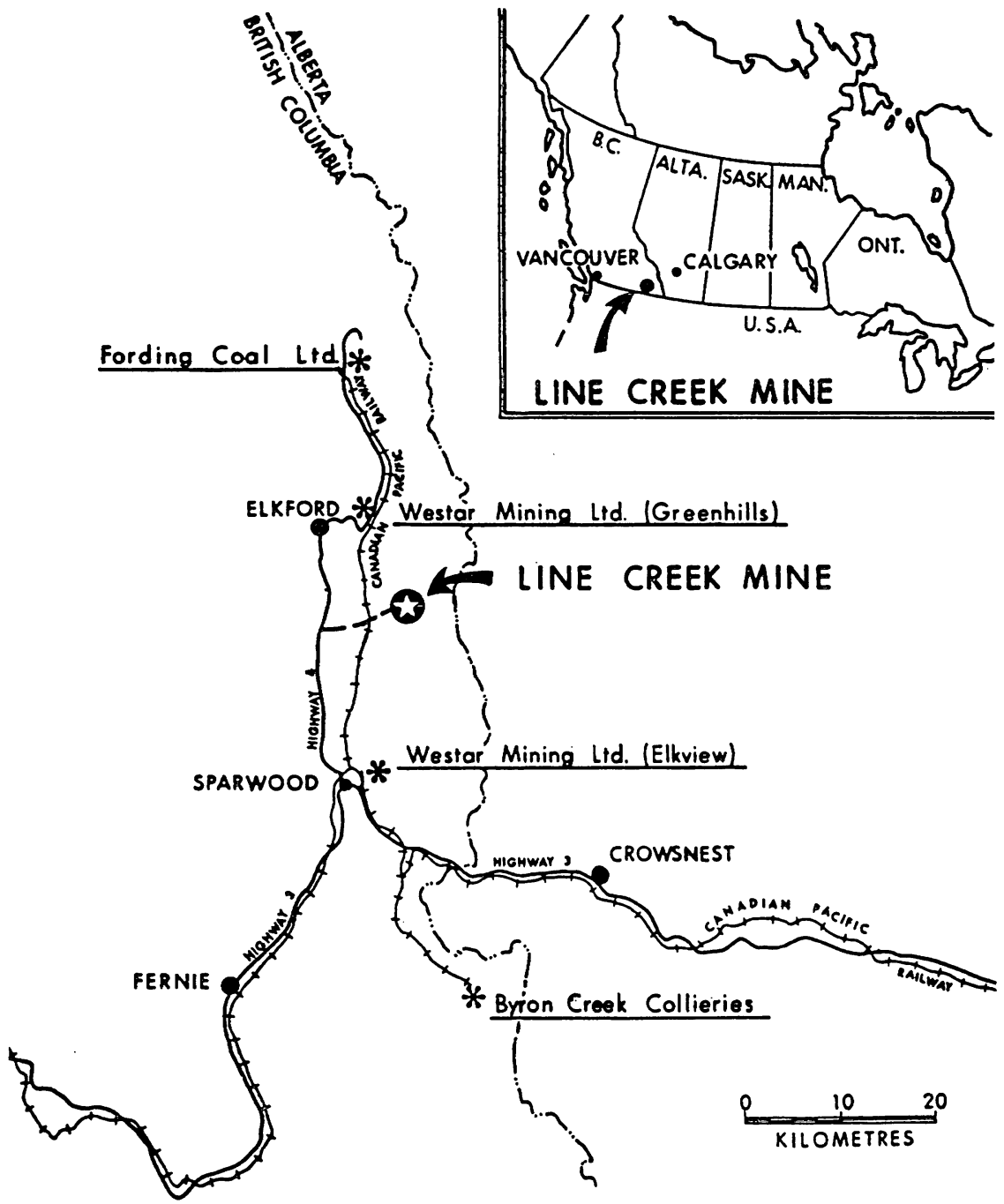

Fig. 1 LINE CREEK LOCATION MAP

coal reserve of 30 million clean tonnes at a stripping ratio of 5.1 cubic meters per raw tonne. The Mine is a multi-bench, open-pit operation. The coal istelf, because of its friable nature, is not blasted or ripped, but is recovered by a front shovel and backhoe combination. The coal is hauled 16 kilometers from the Mine to the Plant by 40 -tonne trucks.

\section{GOAL PROGESSING}

The Line Creek Mine is unique in North America in its design of two separate processing facilities, one for metallurgical coal and one for thermal coal. The two products are processed completely independently from the dump station to the clean coal silos. (see Figure 2)

The Thermal Coal Plant was commissioned in February 1982, with the first vessel loading in April 1982. The Metallurgical Plant was commissioned in January 1983. Shipment of metallurgical coal from the Roberts Bank port to the Japanese Steel Mills commences in Apirl 1983. 
Table 1 QUALITY CHARACTERISTICS OF LINE CREEK CLEAN COAL

\begin{tabular}{|c|c|c|c|}
\hline PARAMETER & BASIS & THERMAL & $\begin{array}{l}\text { METALLU- } \\
\text { RGICAL }\end{array}$ \\
\hline \multicolumn{4}{|l|}{ MOISTURE } \\
\hline Total & A. $R$. & $6.0-8.0$ & $6.0-8.0$ \\
\hline Residual & A. D. & $0.7-1.3$ & $0.4-0.6$ \\
\hline \multicolumn{4}{|l|}{ PROXIMATE } \\
\hline Ash & A. D. & $15.0-17.0$ & 9.5 \\
\hline Volatiles & A. D. & $20.5-21.5$ & $21.0-22.0$ \\
\hline Sulphur & A. D. & $0.3-0.4$ & $0.3-0.4$ \\
\hline ULTIMATE & DAF & & \\
\hline Carbon & $\%$ & 85.85 & 85.85 \\
\hline Hydrogen & $\%$ & 4.67 & 4.67 \\
\hline Nitrogen & $\%$ & 1.10 & 1.10 \\
\hline Sulphur & $\%$ & 0.37 & 0.37 \\
\hline Oxygen & $\%$ & 8.01 & 8.01 \\
\hline GROSS CALORIFIC VALUE & KCAL/KG. A. D. & $6,700-6,900$ & 7,700 \\
\hline HARDGROVE GRINDABILITY INDEX & & 75.0 & 75.0 \\
\hline ASH FUSION TEMP. & IDT ${ }^{\circ} \mathrm{C}$ & $1,450.0$ & $1,450.0$ \\
\hline SIZE & MM & $0-50$ & $0-50$ \\
\hline FREE SWELLING INDEX & & - & $5.0-7.0$ \\
\hline MAXIMUM GIESELER FLUIDITY & DDPM & - & 10.0 \\
\hline TOTAL DILATATION & & - & 10.0 \\
\hline \multicolumn{4}{|l|}{ COKE STRENGTH- } \\
\hline JIS DI $30 / 15$ & & - & 93.5 \\
\hline JIS DI $150 / 15$ & & - & 83.1 \\
\hline ASTM STABILITY & & - & 53.0 \\
\hline ASTM HARDNESS & & - & 69.0 \\
\hline
\end{tabular}

\subsection{Run-Of-Mine Coal Gircuit}

The Run-Of-Mine coal is delivered to the bifurcated truck dump; one side receiving metallurgical coal and the other side thermal coal. Each coal has an identical but separate circuit in the Breaker Station where the material is reduced in size to minus $50 \mathrm{~mm}$. From the Breaker Station the raw coals are conveyed to five 5000-tonne capacity raw coal silos. Two silos are used for thermal coal and three silos are designated for metallurgical coal. The silos enhance overall quality control by permitting controlled blending of coals from the different seams.

\subsection{Thermal Goal Preparation Plant}

The nature of the Line Creek coal permits partial washing in the plant at a design capacity of 272 raw tonnes-per-hour. (Figure 3). The raw coal is dry screened at a nominal size of $6 \mathrm{~mm}$, with the undersize passing through directly as clean coal product. The $50 \times 6 \mathrm{~mm}$ material is cleaned in a Daniels heavy medium vessel. The clean coal from the vessel is mechanically dried by a basket centrifuge prior to discharge onto the clean coal conveyor where it is combined with the minus $6 \mathrm{~mm}$ fraction. Automatic sampling of the total clean coal takes place before storage in the 13,600-tonne capacity clean coal silo. The partial washing concept eliminates the need for thermal drying of the product.

\subsection{Metallurgical Coal Preparation Plant}

The metallurgical coal preparation process represents a typical Western Canadian design, in- 


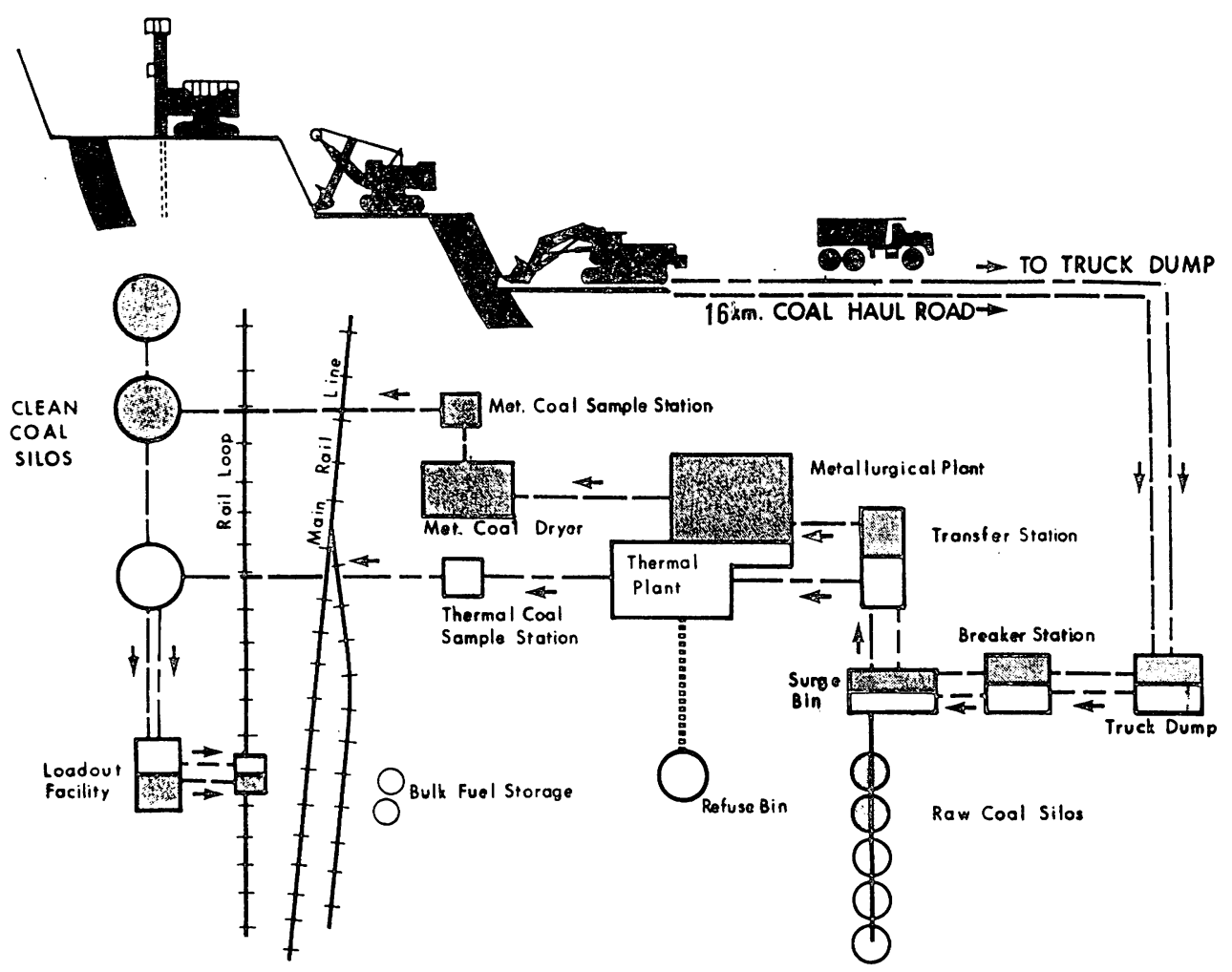

Fig. 2 GENERAL LINE CREEK MINE FLOWSHEET

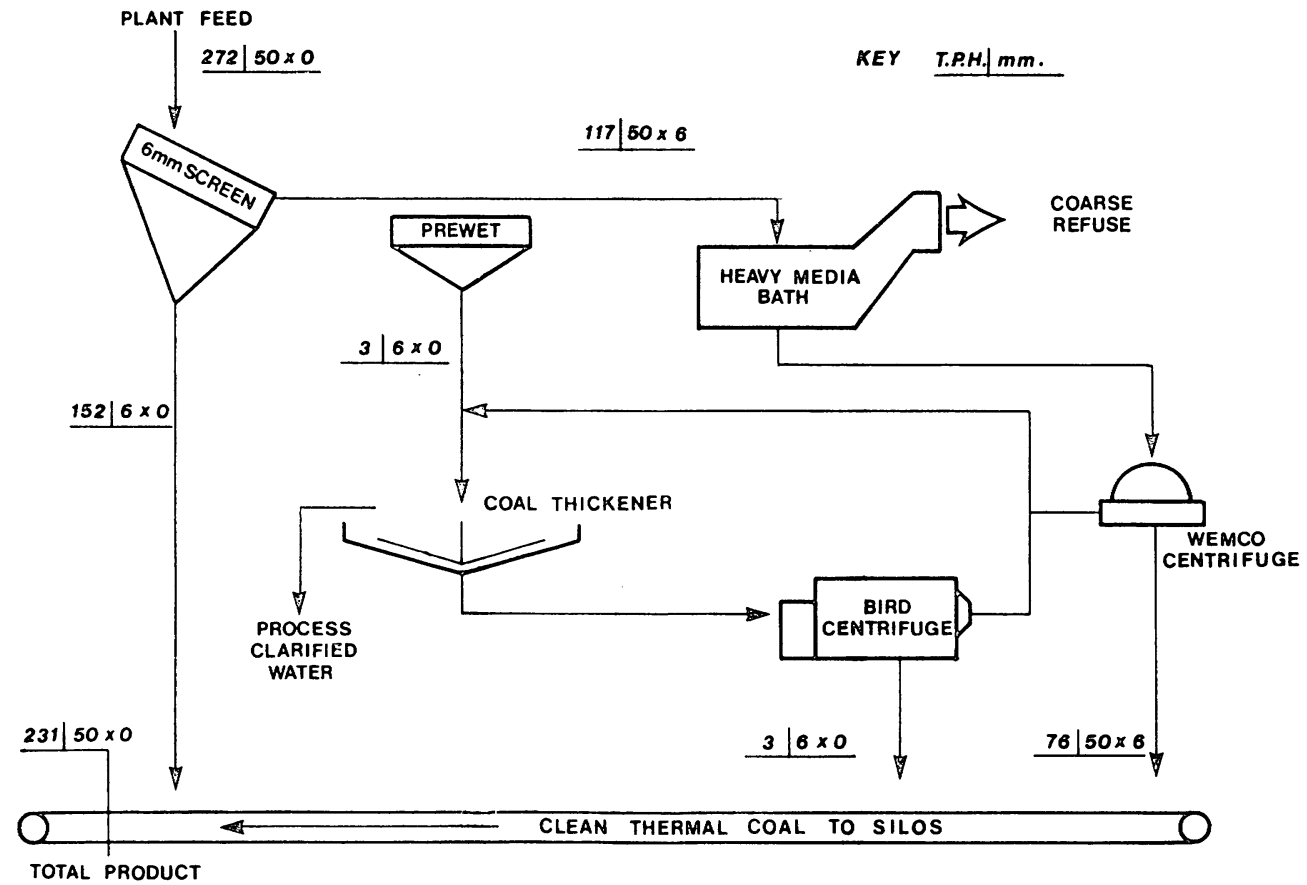

Fig. 3 THERMAL COAL PREPARATION PLANT 


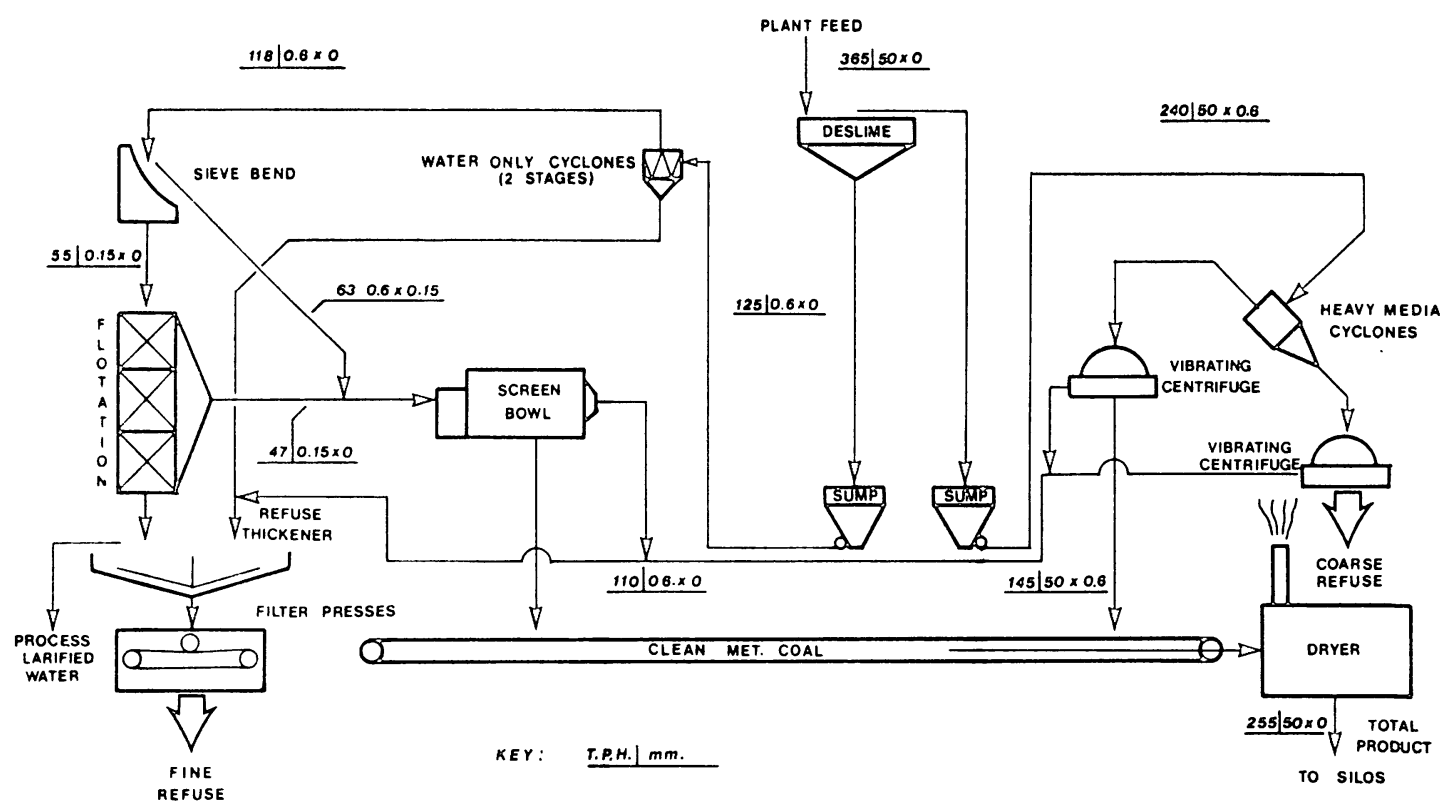

Fig. 4 METALLURGICAL COAL PREPARATION PLANT

cluding a high emphasis on cleaning of fine coal. The design capacity is rated at 365 tonnes-an-hour. (Figure 4)

The raw coal is screened on four deslime screens at $0.6 \mathrm{~mm}$, with the $50 \times 0.6 \mathrm{~mm}$ raw coal passing to the heavy medium sumps. This plus $0.6 \mathrm{~mm}$ coal is pumped to the four $600 \mathrm{~mm}$ diameter heavy media cyclones. Both the clean coal product and the refuse are passed over drain-and-rinse screens and are subsequently dewatered in basket centrifuges.

The minus $0.6 \mathrm{~mm}$ coal is collected in a fine coal sump from which it is pumped to a two-stage water-only cyclone circuit. There are $24-300 \mathrm{~mm}$ primary and 6-300 $\mathrm{mm}$ secondary cyclones. The product from the water-only cyclone circuit is pumped to the vibrating sieve bends for a classification at $0.15 \mathrm{~mm}$. The minus $0.15 \mathrm{~mm}$ underflow of the sieve bends forms the feed to the two banks of six $8.5 \mathrm{~m}^{3}$ froth flotation cells. The froth flotation product is blended with the plus $0.15 \mathrm{~mm}$ overflow from the vibrating sieve bends for dewatering in the three $1100 \times 3300 \mathrm{~mm}$ screen bowl centrifuges. The coarse and the fine clean coal products are collected on the clean coal conveyor and fed to a gas-fired fluidized bed thermal dryer for further moisture reduction. Automatic sampling takes place prior to storage of the dried clean coal product in either one of two available 13,600-tonne clean coal silos.

\subsection{Refuse Disposal}

The coarse refuse from the Thermal Plant as well as all the refuse from the Metallurgical Plant is handled by a common refuse conveyor and disposal bin. The combined refuse is hauled by truck to the disposal site.

Of specific interest is the application of continuous belt filter presses in the fine refuse recovery process. This will be highlighted in detail in the discussion of the closed water circuit.

\subsection{Rail Transportation}

The Line Creek Mine is serviced by the Canadian Pacific Railway, one of the pioneers in the development of unit train coal movements. 
The clean coal is drawn from the clean coal silos by variable speed belt feeders. Each silo has seven feeders, three in-line feeders and four side feeders.

The actual loadout operation is semi-automatic and computer assisted. As not all cars in the unit train are of the same capacity, the train consist is telexed to the Loadout Operator in advance of train loading. This information is entered into the computer, together with the gross load limit of each loaded car. On the approach to the loadout, each empty car passes over a track scale. The actual weight of the car is automatically relayed to the computer and the required tonnage to be delivered into each car is determined by the formula: gross load limit minus actual weight of the car prior to loading.

Clean coal reclaimed from the clean coal storage is conveyed to a 200 -tonne loadout bin equipped with gates to start and stop the flow of coal. The opening of the bin gates is determined by Operator command. A high accuracy belt scale $( \pm 0.5 \%)$ weighs the coal conveyed to each car. The computer receives this information and closes the gates when the predetermined required tonnage is delivered.

A unit train consists of 108 cars at 92 tonnes each and is loaded at a rate of about 3000 tonnesan-hour. A dust suppressant coating is sprayed on each car to minimize losses due to dusting during transportation and to meet environmental standards during the 1100 kilometer journey to Roberts Bank near Vancouver.

\section{THE GLOSED WATER GIRGUIT}

During the early stages in the development of the Line Creek Mine, Crows Nest Resources Limited made a commitment to operate their Coal Preparation Plants with closed water circuits. A key design consideration for each Coal Preparation Plant was to accommodate the recovery and disposal of dewatered fine refuse.

Initially it was intended to incorporate solid bowl centrifuge technology for this purpose. However it was perceived that the high moisture content of the dewatered product would result in a handling problem. It was decided to investigate alternatives to solid bowl centrifuges for this specific application.

The continuous belt filter press was rather new in the coal preparation field. There was only one unit in operation in North America, this was at the W.I.D.C.O. nore: Single space only Plant in Centralia, Washington, where it was used primarily for the dewatering of bentonitic clay refuse. The results at W.I.D.C.O. were very encouraging. Investigations into this type of dewatering equipment led to contacts with Dr. B. Bogenschneider of BAG Niederrhein, a Division of Ruhrkohle AG in West Germany. Extensive full-scale studies in the field of coal tailings dewatering had been carried out under his directions at their Lohberg Plant. Vacuum-band filters and belt filter presses offered by various manufacturers were evaluated for the disposability of the product. A study visit was made upon invitation of Dr. Bogenschenider. The selection of the continuous belt filter presses was indicated to be the best approach to meet the specific needs of the Line Creek Plant operation.

A pilot trail with a 1 meter belt filter press was arranged in cooperation with a neighbouring Coal Preparation Plant and the Arus-Andritz Company. After extensive analysis of the gathered data, the decision was made to purchase Arus-Andritz continuous belt filter presses, Type S-7.

As with any dewatering system, the conditioning of the feed is crucial for a good operation. This placed specific requirements on the selection of the thickener/clarifier. A high capacity 
Enviro Clear thickener was chosen to meet the process requirements. This thickener is deisgned for quick settling of suspended particles and is much smaller than a conventional thickener for a similar duty: 16,700 $\mathrm{mm}$ diameter versus 44,200 $\mathrm{mm}$ diameter for a conventional unit. An added benefit was the fact that this smaller thickener could be installed inside the Plant Building. Thickened slurry at 30 to $36 \%$ solids is transferred to the filter presses by variable speed centrifugal pumps. Flocculant addition points were installed throughout the circuit to provide maximum opportunity for experimentation.

The closed water loop and the fine refuse dewatering process is an integral part of the production process, which could present major limitations to Line Creek's capability to produce coal. The attitude of the operating personnel and their level of technical understanding would determine the success of the operation. This concept is reflected in the personnel selection process and an intensive training program, including classroom education, that supports the Operators at each stage of their careers.

The short circuit demands fast response to changing operating conditions. The level of authority is high and includes full control of process adjustments and flocculants addition. Extensive records are kept to evaluate cause-and-effect relationship throughout the entire circuit.

\subsection{Operating Description}

The Enviro Clear thickener underflow is pumped to a distributor tank, from where it is transferred to the belt filter presses. The number of presses in use at any given time is governed by process conditions.

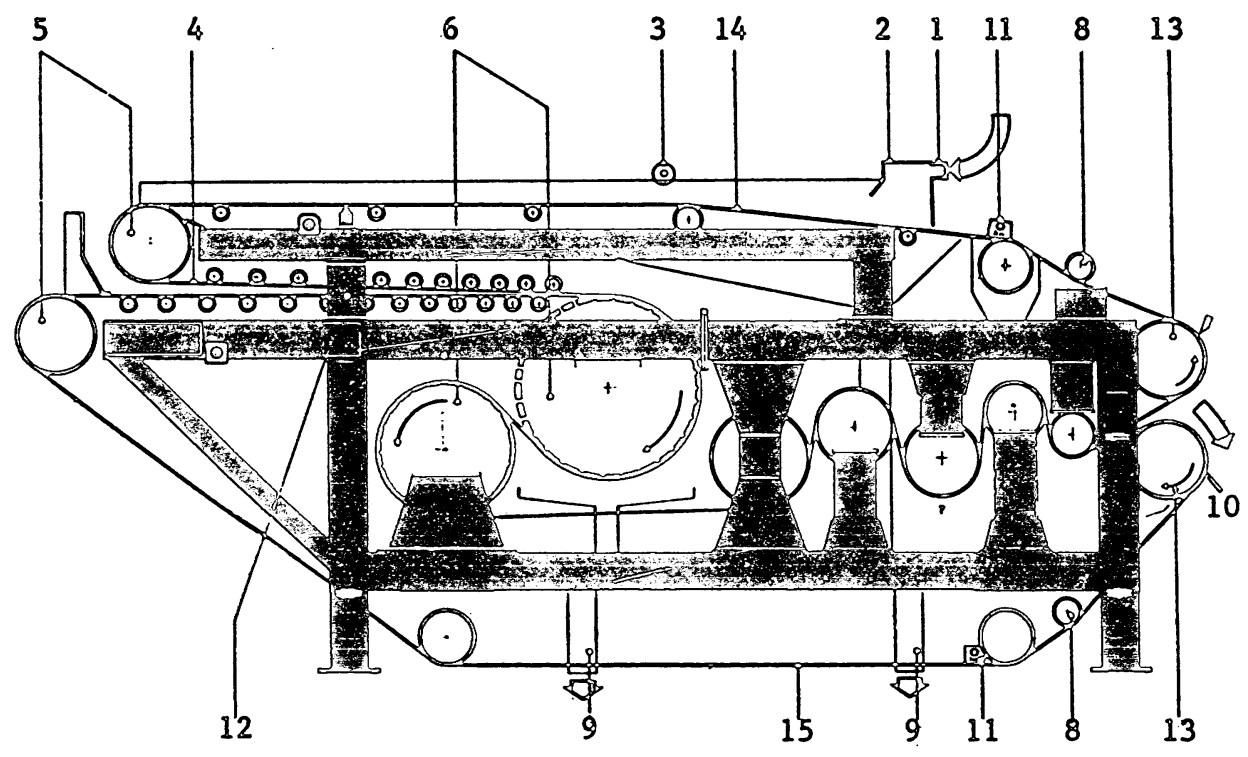

Fig. 5

1 Sludge/slurry feed 2 headbox 3 Equipment for distribution and loosening or the cake 4 Wedge zone with table rolls 5 Wire belt tensloning rolls (breast rolls) 6 Medium pressure-Prepress zone (perforated drums) 7 High pressure-Main press zone (5-rolls) Smodule) 8 Spreader rolls (only for SDM 3500 S7) 9 Filtrate drain 10 Cake discharge 11 Wire belt cleaning device 12 Loose pieces of the machine frame for exchange of the endless wire belts (Cantllever system) 13 Forward drive rolls 14 Top wire belt 15 Bottom wire belt 
The feedlines to the presses are equipped with in-line static mixers. These mixers keep the suspended solids from settling out and thus prevent the presence of free water at the feed introduction to the presses. They also promote good flocculant/solid contact.

The flocculated tailings stream is introduced at the headbox, (Item 1 and 2) shown in Figure 5. Gravity drainage is immediate. The cake passes through a spreading screw arrangment and is distributed over the full width of the belt. Gravity drainage is maintained until the material drops onto the bottom belt. A gentle squeezing is started in the wedge zone as the top and bottom belts are gradually brought together. Water is released through both the top and the bottom belt. As the water content is decreased, the pressure on the cake is increased (Item 4). Water release through both belts is continued as the material is moved around the perforated drums (Item 6). The 5-roll S-module, made of rolls of decreasing size, forms the high pressure zone (Item 7). The cake is discharged (Item 10) and the belts are cleaned in washboxes (Item 11) to prevent clogging of the fabric.

The cake has good handling characteristics. It is very compact due to both the pressure and the friction action created by the speed differential between the two belts while passing around the rolls.

The filtrate is gathered in a number of drainage trays (Item 9) and ultimately returned to the thickener for re-use in the Plant process.

\subsection{Experience To-Date}

The belt filter presses are of sturdy construction and operate at slow speed. Maintenance has not been a problem. A common area of concern in the use of this equipment, is the life of the belts. In our operation we have a belt life of six months which corresponds with the anticipated life. Recent improvements in operating techniques will extend the belt life considerably.

The following is a listing of design performance specifications compared with actual results:

$\begin{array}{lcc} & \text { DESIGN } & \text { ACTUAL } \\ \text { Feed Rate (tonne/hr.) } & 16 & 14-19 \\ \% \mathrm{H}_{2} \mathrm{O} \text { in Product } & 27 & 23-30 \\ \text { Flocculant-Anionic }(\mathrm{kg} / \mathrm{t}) & 0.15 & 0.25 \\ \text { Flocculant-Cationic }(\mathrm{kg} / \mathrm{t}) & 0.35 & 0.15 \\ \text { Capture Rate }(\%) & 98 & 98\end{array}$

An extensive flocculant testing program on the fine refuse has been completed. Line Creek is presently engaged in full scale test program of alternative flocculants.

\section{QUALITY GON'TROL PROGRAM}

This review deals with the quality control program as it relates to the production of metallurgical coal only. Thermal coal quality is monitored in a similar fashion.

A schematic representation of the quality control program is provided in Figure 6.

\subsection{Mine}

A reverse circulation exploration drill $(130 \mathrm{~mm})$ is used to drill through the coal seams in advance of mining. Coal is sampled and analyzed for ash and FSI. The Mine Planning group utilizes this data to develop and allocate the areas for thermal and metallurgical coal production.

Of particular importance are the FSI measurements for the determination of the thermal/metallurgical boundaries. The cutoff point is 4 FSI. The results of this pre-production drilling and 


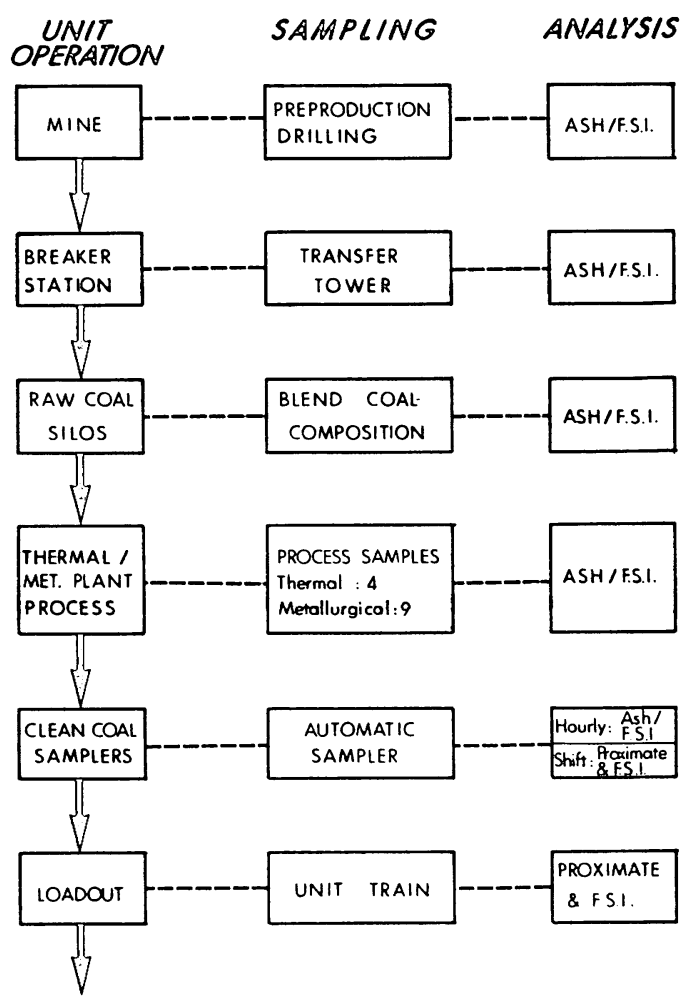

Fig. 6 QUALITY CONTROL FLOWSHEET

sampling program are incorporated to the short term mining plans. Weekly meetings are held by the Mine Planning group with representatives of the Mine Production and Plant Operating personnel. The coal release program for the following ten days is discussed in detail and the impact of this program is tested with operating needs and specific conditions.

\subsection{Breeker Station}

The Run-Of-Mine coal is sampled at the Breaker Station. This sampling program has a dual purpose :

1) It provides data to determine whether or not the anticipated quality parameters are being met. The ash levels indicate possible dilution levels as well as variations in FSI. This information is exchanged with Mine Production personnel.

2) The generated analysis provides the Plant Operating group with the required information of the coal in the Raw Coal Silos. Such data base is needed for a rational approach to the blending of the raw coals at a later stage.

The samples are taken manually and are analyzed every four hours for ash and FSI.

\subsection{Raw Coal Silos}

The use of silos accommodates storage of the raw coals by individual seams. This feature allows for controlled blending of the raw coal stream to the Plant. Each silo is equipped with a variable speed belt feeder with a range from 40 to 400 tonnes per hour. Belt scales between the silos provide accurate information about the blend ratios.

Considerations in the composition of the raw coal feed blends are: 
-ash levels of the coals,

-size distribution,

-size/ash relationship,

-processing conditions.

Manual samples are taken from the Plant stream on an hourly basis and are analyzed for ash and FSI as a shift composite.

\subsection{Coal Preparation Plant}

An automatic sampler removes a sample of clean coal every four minutes. The four-minute increments are composited every hour and analyzed for ash and FSI. Every twelve hours a shift composite is prepared and a full proximate analysis and FSI is performed.

Deviations from target coal quality, as determined by the hourly analysis, are generally controlled by process adjustments. Such process adjustments include reduction in throughput, changes in heavy media specific gravity, variations in reagent dosages or modifications in blending ratios from the raw coal silos.

This effort is supported by a process control program. The feed, product and waste of each process stream is sampled every hour and analyzed as a shift composite. The result is a full AshBalance of the whole process. The Ash-Balance is used to check the process efficiency. It provides norms for a good operation, updates experience and maintains quality awareness as an integral part of processing.

\subsection{Loadout}

A small sampler built into the loadout bin bi-parting gates extracts a sample with each opening and closing motion of the gates. This provides a sample for each car. The final sample weighs approximately 120 kilograms. A full proximate analysis and FSI is performed. It is common practice to trace the coal back to production and to calculate train quality based on the shift results as well. This provides the last check in our quality control program.

It should be noted that clean coal quality and plant yield are reported back to the Mine Planning group, thus completing the quality program circle.

\section{GONGLUSION}

-The first year of operation indicates that the Thermal and Metallurgical Plant design are well matched to multi-seam mining.

-The closed water circuit has been operated successfully.

-The quality control program has contributed to a stable operation and consistency of product.

Crows Nest Resources Limited is proud of the result achieved to-date. They are confident that the challenges of the future will be met through cooperation, increased levels of knowledge and plain hard work by all. 